\title{
Struvite infection calculi in dogs: Problems with urinary calculus identification, and the value of the results
}

\author{
John Dunlevey $^{a \star}$ and Michael Laing ${ }^{b}$
}

DENTIFYING THE CRYSTALLINE COMPONENTS

of a urinary calculus is a valuable aid to correct diagnosis, and subsequent treatment of the underlying cause of the problem. Calculus formation is often an end product brought about by urine with a high concentration of insoluble material causing bladder irritation. This promotes bacterial infection by Proteus, which not only raises the $\mathrm{pH}$ in the bladder and generates ammonia, but also provides sites for mineral nucleation and crystal growth. Treating the infection and removing the stone will not necessarily cure the disorder. Correct identification of a calculus as struvite and even its potassium analogue can be critical in choice of curative protocols, but this is not always straightforward. Our experience with 'problem calculi' is described.

\section{Introduction}

We have been systematically analysing urinary calculi by the $X$-ray powder diffraction method since 1978, in both humans and domestic animals. ${ }^{1-3}$ The formation of a struvite calculus is normally due to the presence of ammonia and a raised $\mathrm{pH}$ in the urine, caused by infection. We have found over the past four years that some struvite bladder calculi from dogs display abnormal intensity peak patterns that are ${ }^{a}$ School of Earth Science, University of KwaZulu-Natal, Durban 4041, South Africa.

${ }^{b}$ School of Pure and Applied Chemistry, University of KwaZulu-Natal, Durban.

*Author for correspondence.

E-mail: dunleveyj@ukzn.ac.za not immediately identifiable, even through the $d$-spacings of the planes appear to be generally correct. ${ }^{4}$ These discrepancies are so large as to be of significance and warrant reporting.

\section{Experimental}

X-ray powder diffraction (XRD) patterns were recorded with cobalt $\mathrm{K}_{\alpha}$ radiation $(\lambda=1.7889 \AA)$ as described in ref. 1. A selection of observed patterns is shown in Fig. A (see supplementary material online), and a list of the $d$-spacings and the relative intensities of diffraction peaks are given in Table 1 (online). The calculi were also analysed for the presence of various chemical elements using the EDAX technique on a JEOL scanning electron microscope, because the presence of calcium is indicative of amorphous hydroxyl apatite, which often exists as an amorphous solid and is therefore not evident in the XRD scan.

\section{Results}

Typical analytical data are presented in Fig. B (online). The results from a collection of struvite stones are given in Fig. 1 and Fig. A (online). A comparison of the observed peak intensities (Table 1) with the standard pattern ${ }^{4}$ shows quite clearly that few of the samples (e.g. A-D, Table 1) give the 'normal' intensity distribution. For convenience, the diffraction patterns in Table 1 are grouped by the common most intense diffraction peak, which arises from the 4.26, 5.60, 2.69 and $4.13 \AA$ planes. The powder diffraction patterns in Fig. A illustrate the problem, and it is hard to believe that all were generated from the same crystalline compound. Thus, there will be a major problem if one uses the set of four strongest lines as the primary criterion (Hanawaldt search) for identifying the 'unknown'. However, there are always the same groups of $d$-spacings with strong reflections $\{5.90$, $5.60,5.38\} ;\{4.26,4.13\} ;\{2.80,2.69,2.66\}$, but the strongest may occur in any of the three groups (compare the examples in Table 1: Suzy $5.60 \AA$ [G]; Dallas $4.26 \AA$ [D]; Cleo $2.80 \AA[S]$ and Cheeky $2.69 \AA$ [U]).

\section{The problem of potassium}

The most commonly occurring mineral species in calculi from dogs is struvite, an ammonium magnesium phosphate hydrate $\left[\mathrm{NH}_{4} \mathrm{MgPO}_{4} \cdot 6 \mathrm{H}_{2} \mathrm{O}\right]$. However, we were surprised when potassium was detected by EDAX in several of the stones. It transpires that a well-defined potassium analogue $\left[\mathrm{KMgPO}_{4} \cdot 6 \mathrm{H}_{2} \mathrm{O}\right]$ of struvite exists, where $\mathrm{K}^{+}$replaces the $\mathrm{NH}_{4}^{+}$ammonium cations. These two compounds are isostructural, ${ }^{6,7}$ with the existence of a complete isomorphous series from $100 \%$ $\mathrm{K}^{+}$to $100 \% \mathrm{NH}_{4}^{+}$struvite. ${ }^{6}$ This ion replacement is possible, as the ionic radii of $\mathrm{K}^{+}$and $\mathrm{NH}_{4}^{+}$are almost identical ${ }^{8}$ (1.52 vs $1.51 \AA$ ).

It is evident that when the struvite (infection) calculus forms and is growing, any potassium present in the urine can be incorporated into the crystal structure of the stone. This potassium can be detected by EDAX, but can also show itself by subtle effect on all the $d$-spacings (those of ideal pure struvite are about $2 \%$ greater than 

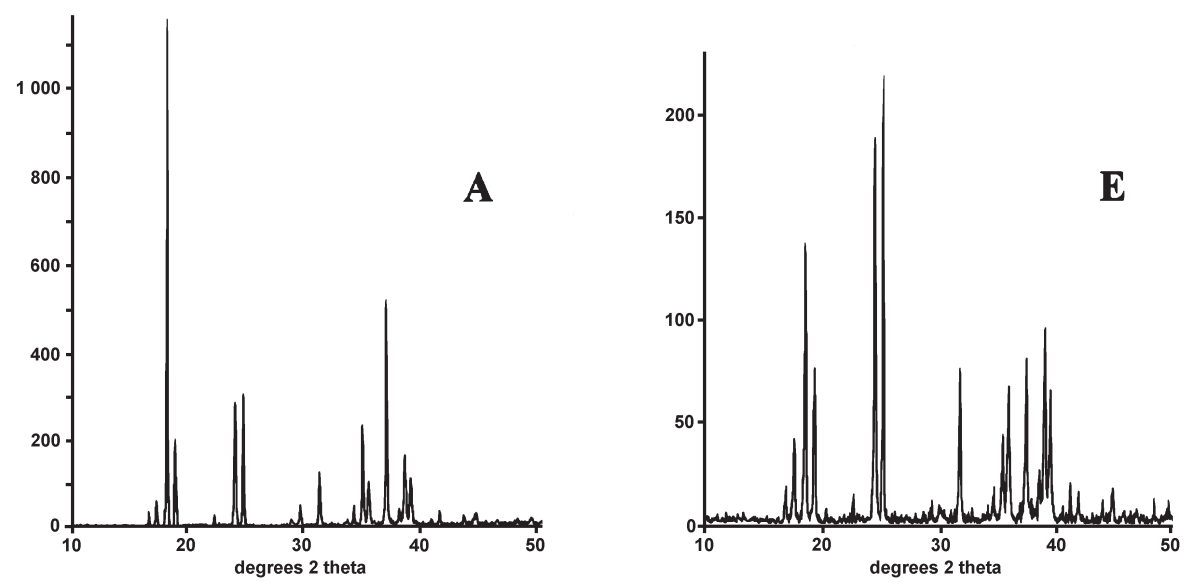

Fig. 1. Two examples of observed X-ray powder diffraction patterns of struvite calculi. In all cases, the $d$-spacings (values of $2 \theta$ ) are the same for the important lines, but the relative intensities vary greatly. In $A$ the peak at $19^{\circ}$ is far higher than the pair at $24^{\circ} 2 \theta$. In E the situation is reversed; the pair at $24^{\circ}$ is the strongest. These anomalous intensities can make identifying the calculus as struvite difficult if only the three or four strongest lines are used as the criterion in searching the Powder Diffraction File. Using the seven strongest lines, and ignoring the relative intensities, normally will identify the species as struvite. Neither scan has obvious high backgrounds, nor are there the broad peaks due to poorly crystalline hydroxyl apatite $\left(2.81-2.72 \AA \AA 37-38^{\circ} 2 \theta\right)$. Six additional scans of this kind are reproduced in Fig. A online.

those of the potassium analogue). Table 2 (see supplementary material online) compares the unit cell dimensions and important $d$-spacings of the two crystalline compounds. It is clear that material that contains both $\mathrm{K}^{+}$and $\mathrm{NH}_{4}^{+}$cations will have $d$-spacings of intermediate size; but the effect is very small, with differences being detectable only in the second decimal place of the $d$-spacing. Unfortunately, this level of precision is not usually attainable during typical routine powder diffraction analysis of calculi samples.

Figures C and D (both online) are projections of the crystal structures along the $b$-axis. It is evident that the site occupied by the $\mathrm{K}^{+}$and $\mathrm{NH}_{4}{ }^{+}$ions lies on the 110 , 020, 021, 200 and 130 planes and diffraction from these should be most affected by the replacement of $\mathrm{NH}_{4}^{+}$by $\mathrm{K}^{+}$ (Table 2).

\section{An unusual result}

Calcium is regularly found in calculi, ${ }^{2,3}$ most commonly as the phosphate [hydroxyl apatite $\mathrm{Ca}_{5}\left(\mathrm{PO}_{4}\right)_{3}(\mathrm{OH})$ ] and less often as an oxalate [monohydrate whewellite $\mathrm{CaC}_{2} \mathrm{O}_{4} \cdot \mathrm{H}_{2} \mathrm{O}$; dihydrate weddelite $\mathrm{CaC}_{2} \mathrm{O}_{4} \cdot 2 \mathrm{H}_{2} \mathrm{O}$ ]. The struvite calculi from the dog named Rambo consist of two types of material: (i) dark, hard, containing only magnesium (typical struvite); (ii) softer, granular containing some calcium. The intensities of the diffraction peaks from the type (ii) material were distinctly weaker than those from the type (i) material, indicating that type (ii) was less crystalline, that is, the internal structure was not as regular as in the ideal struvite structure. Close analysis of the XRD powder pattern reveals a broad background hump between $35^{\circ}$ and $39^{\circ} 2 \theta$ ( $d$-spacing between 2.72 and $2.81 \AA$ ) and hydroxyl apatite. The presence of apatite in a calculus is indicative of hyperparathyroidism. ${ }^{1,2}$

\section{Discussion}

The anomalous intensity patterns are immediately obvious and can arise from several sources. Examples are: orientation effects from abnormal crystal shape due to the mode of crystal growth; ${ }^{10}$ particle size effects; degree of pressure during grinding of the sample; loss of water from the crystal structure; isomorphous replacement of some magnesium by calcium, or ammonium by potassium. Our results show that there is no direct correlation between calcium content and the magnitude or pattern of anomalies in the X-ray powder patterns of the struvite in these stones. Where calcium is detected by EDAX or XRF, it is usually associated with solid, amorphous, hydroxyl apatite.

The results show that there are two types of complementary information obtainable. X-Ray powder diffraction immediately identifies the calculus as a 'struvite infection' stone, and thus the patient can be treated appropriately. However, identifying the presence of calcium and/or potassium by EDAX can indicates the presence of amorphous give an important indication of the underlying problem. For example, calcium, present as amorphous hydroxyl apatite, may indicate a malfunction of the dog's parathyroid gland. If a dog presents a bladder calculus, it may be of value to routinely check the urine for $\mathrm{pH}$ as well as for ammonia, which may indicate infection. An excessively high result for potassium may be an indicator for the underlying cause of calculus formation.

\section{Conclusions}

We offer the above experiences as a salutary example to other researchers who may be using the X-ray powder diffraction technique. Do not be misled (as we were initially) by 'missing lines' and 'wrong intensities'. These anomalies are not uncommon, and their identification may provide valuable hints of minor but important complexities associated with the condition that generated the stone. Should any readers wish to have urinary calculi analysed by XRD (canine, feline or human), we would be pleased to have them as contributors to this continuing research project.

We thank the University of KwaZulu-Natal for supporting this research project and providing access to the XRD and SEM EDAX equipment. We acknowledge the assistance of the late F. Graham, and D. Rabie (Umbilo Veterinary Clinic) as well as the many pet owners who have donated the calculi removed from their dogs.

Received 6 June. Accepted 20 August 2008.

1. Gray D., Laing M., Nel F. and Naude J.H. (1982). Composition of urinary calculi collected in the Durban area. S. Afr. Med. J. 61, 121-125.

2. Laing M., Kerr A. and Nel F. (1993). Fifteen years and $5000 \mathrm{X}$-ray patterns later: renal stone analysis at the University of Natal, Durban. S. Afr. J. Sci. 89, 528-530.

3. Laing M. and Dunlevey J. (2000). A novel urinary calculus from Felis catus. S. Afr. J. Sci. 96, 220-221.

4. JCPDS (1997). Powder Diffraction File 15-762. ICDD, Walnut Street, Philadelphia, PA.

5. Banks E., Chianelli R. and Korenstein R. (1975). Crystal chemistry of struvite analogs of the type $\mathrm{MgMPO}_{4} \cdot 6 \mathrm{H}_{2} \mathrm{O}\left(\mathrm{M}^{+}=\mathrm{K}^{+}, \mathrm{Rb}^{+}, \mathrm{Cs}^{+}, \mathrm{Tl}^{+}, \mathrm{NH}_{4}^{+}\right)$. Inorg. Chem. 14, 1634-1639.

6. Mathew M. and Schroeder L.W. (1979). Crystal structure of a struvite analogue $\mathrm{MgKPO}_{4} \cdot 6 \mathrm{H}_{2} \mathrm{O}$. Acta Cryst. B35, 11-13.

7. Whitaker A. and Jeffery J.W. (1970). The crystal structure of struvite $\mathrm{MgNH}_{4} \mathrm{PO}_{4} \cdot 6 \mathrm{H}_{2} \mathrm{O}$. Acta Cryst. B26, 1429-1440.

8. Huheey J.E., Keiter E.A. and Keiter R.L. (1993). Inorganic Chemistry, 4th edn. HarperCollins, New York.

9. JCPDS (1997). Powder Diffraction File patterns 15-762 and 35-812. ICDD, Walnut Street, Philadelphia, PA.

10. Abbona F., Calleri M. and Ivaldi G. (1984). Synthetic struvite $\mathrm{MgNH}_{4} \mathrm{PO}_{4} \cdot 6 \mathrm{H}_{2} \mathrm{O}$ correct polarity and surface features of some complementary forms. Acta Cryst. B40, 223-227.

This article is accompanied by supplementary analytical and crystallographic results in tabular and graphical form online at www.sajs.co.za 


\section{Supplementary material to:}

Dunlevey J. and Laing M. (2008). Struvite infection calculi in dogs: Problems with urinary calculus identification, and the value of the results. S. Afr. J. Sci. 104, 471-472.

Table 1. A comparison of the X-ray powder diffraction peaks of synthetic struvite (ICDD data file 15-762) with those struvite calculi recovered from 21 pet dogs.

\begin{tabular}{|c|c|c|c|c|c|c|c|c|c|c|c|c|c|c|c|c|c|c|c|c|c|c|c|}
\hline No. & $d(\AA \AA)$ & $I_{\text {rel }}$ & A & B & C & D & $\mathrm{E}$ & $\mathrm{F}$ & $\mathrm{G}$ & $\mathrm{H}$ & 1 & $\mathrm{~J}$ & $\mathrm{~K}$ & $\mathrm{~L}$ & M & $N$ & 0 & $P$ & Q & $\mathrm{R}$ & $S$ & $\mathrm{~T}$ & $U$ \\
\hline 1 & 6.13 & 8 & 6 & 10 & 9 & 11 & 7 & 20 & 11 & 3 & 13 & 7 & 1 & 2 & 3 & 4 & 1 & 11 & 4 & 7 & 2 & 3 & 13 \\
\hline 2 & 6.90 & 40 & 10 & 30 & 18 & 35 & 12 & $<1$ & 40 & 10 & 24 & 24 & 9 & 5 & 10 & 27 & 5 & 14 & 18 & 4 & 11 & 6 & 15 \\
\hline 3 & 5.60 & 60 & 91 & 97 & 55 & 79 & 100 & 100 & 100 & 100 & 100 & 100 & 100 & 100 & 100 & 96 & 41 & 58 & 60 & 70 & 28 & 77 & 82 \\
\hline 4 & 5.38 & 25 & 59 & 51 & 36 & 39 & 50 & 48 & 38 & 24 & 34 & 25 & 15 & 14 & 21 & 45 & 10 & 34 & 29 & 3 & 14 & 24 & 63 \\
\hline 5 & 4.60 & 6 & 3 & 6 & 6 & 7 & 7 & 9 & 10 & 6 & 4 & 4 & 2 & 2 & $<1$ & 2 & $<1$ & 4 & 6 & $<1$ & 1 & 2 & 1 \\
\hline 6 & 2.26 & 100 & 100 & 100 & 100 & 100 & 44 & 24 & 88 & 45 & 79 & 71 & 42 & 22 & 37 & 59 & 20 & 67 & 87 & 9 & 25 & 27 & 70 \\
\hline 7 & 4.13 & 40 & 39 & 78 & 36 & 71 & 24 & 18 & 57 & 73 & 57 & 29 & 19 & 25 & 42 & 20 & 6 & 68 & 100 & 16 & 5 & 24 & 49 \\
\hline 8 & 3.47 & 12 & 2 & 6 & 13 & 5 & 3 & $<1$ & 8 & 3 & 4 & 4 & 1 & 4 & 2 & 10 & 3 & 3 & 3 & $<1$ & 2 & 4 & 5 \\
\hline 9 & 3.29 & 25 & 28 & 18 & 27 & 30 & 7 & 3 & 30 & 25 & 28 & 11 & 4 & 8 & 6 & 8 & 100 & 11 & 26 & 1 & 6 & 6 & 18 \\
\hline 10 & 3.02 & 14 & 4 & 8 & 19 & 14 & 2 & $<1$ & 11 & 8 & 9 & 7 & 3 & 3 & $<1$ & 1 & $<1$ & 3 & 4 & 2 & 1 & 3 & 12 \\
\hline 11 & 2.96 & 25 & 13 & 21 & $<1$ & $<1$ & 10 & $<1$ & 16 & 6 & 15 & 21 & $<1$ & $<1$ & 3 & $<1$ & 3 & 13 & 19 & 4 & $<1$ & 3 & $<1$ \\
\hline 12 & 2.92 & 55 & 15 & 27 & 34 & 40 & 34 & 12 & 29 & 15 & 24 & 32 & 20 & 8 & 8 & 28 & 6 & 17 & 31 & $<1$ & 18 & 9 & 32 \\
\hline 13 & 2.80 & 35 & 45 & 34 & 35 & 28 & 22 & 19 & 59 & 27 & 40 & 57 & 13 & 38 & 47 & 22 & 18 & 21 & 31 & 100 & 100 & 15 & 25 \\
\hline 14 & 2.69 & 50 & 36 & 42 & 46 & 65 & 58 & 14 & 55 & 30 & 43 & 30 & 5 & 12 & 20 & 18 & 29 & 100 & 43 & 8 & 8 & 100 & 100 \\
\hline 15 & 2.66 & 45 & 8 & 17 & 22 & 23 & 22 & $<1$ & 42 & 8 & 24 & 18 & 41 & 8 & 9 & 100 & 36 & 18 & 29 & $<1$ & 11 & 6 & 18 \\
\hline 16 & 2.35 & 12 & 2 & 5 & 4 & 9 & 4 & $<1$ & 16 & 3 & 5 & $<1$ & 1 & $<1$ & 3 & $<1$ & 33 & 4 & 7 & 2 & 2 & 2 & 5 \\
\hline
\end{tabular}

$d(\AA)=d$-spacing and $I_{\text {rel }}=$ intensity, data from JCPDS-ICDD (1993) database; struvite data file 15-762. Sources: A, Suzie H; B, Matie; C, Bugsie; D, Dallas; E, Rambo I; F, Rambo Il; G, Suzy 3; H, Minke; I, Wishbone (outer); J, Mikis; K, Jamie; L, Bayete; M, Bonnie; N, Kaylee A; O, Kaylee B;
P, Suzy N; Q, Thompson; R, Minky (outside); S, Cleo; T, Wishbone; U, Cheeky.

Table 2. Comparison of the unit cell dimensions and $\mathrm{X}$-ray powder diffraction patterns for struvite $\left(\mathrm{NH}_{4} \mathrm{MgPO}_{4} \cdot 6 \mathrm{H}_{2} \mathrm{O}\right)$ and the potassium analogue $\left(\mathrm{KMgPO}_{4} \cdot 6 \mathrm{H}_{2} \mathrm{O}\right)$ in which the $\mathrm{K}^{+}$has replaced the $\mathrm{NH}_{4}$ anmonito

\begin{tabular}{|c|c|c|c|c|}
\hline \multicolumn{5}{|c|}{ Unit cell dimensions } \\
\hline Struvite & 6.945 & 6.136 & 11.208 & 477.58 \\
\hline Potassium struvite & 6.879 & 6.163 & 11.100 & 470.63 \\
\hline \multicolumn{5}{|c|}{ X-Ray powder diffraction data } \\
\hline \multirow[b]{2}{*}{$h \mathrm{kl}$} & \multicolumn{2}{|c|}{$\begin{array}{c}\text { Struvite } \\
\left(\mathrm{NH}_{4} \mathrm{MgPO}_{4} \cdot 6 \mathrm{H}_{2} \mathrm{O}\right)\end{array}$} & \multicolumn{2}{|c|}{$\begin{array}{l}\text { Potassium struvite } \\
\left(\mathrm{KMgPO}_{4} \cdot 6 \mathrm{H}_{2} \mathrm{O}\right)\end{array}$} \\
\hline & $d$-spacing & Relative intensity & $d$-spacing & Relative intensity \\
\hline 110 & 5.905 & 40 & 5.846 & 10 \\
\hline 020 & 5.601 & 60 & 5.551 & 25 \\
\hline 011 & 5.378 & 25 & 5.390 & 18 \\
\hline 111 & 4.257 & 100 & 4.241 & 100 \\
\hline 021 & 4.139 & 40 & 4.123 & 60 \\
\hline 200 & 3.475 & 12 & 3.436 & 20 \\
\hline 130 & 3.289 & 25 & 3.258 & 39 \\
\hline 201 & 3.022 & 14 & 2.969 & 18 \\
\hline 130 & 3.289 & 25 & 3.258 & 39 \\
\hline 201 & 3.022 & 14 & 2.969 & 18 \\
\hline 012 & 2.958 & 25 & 2.923 & 16 \\
\hline 211 & 2.919 & 55 & 2.899 & 64 \\
\hline 040 & 2.802 & 35 & 2.774 & 37 \\
\hline 112 & 2.722 & 16 & 2.726 & 10 \\
\hline 022 & 2.690 & 50 & 2.695 & 55 \\
\hline 221 & 2.660 & 45 & 2.642 & 45 \\
\hline 231 & 2.452 & 12 & 2.332 & 12 \\
\hline
\end{tabular}



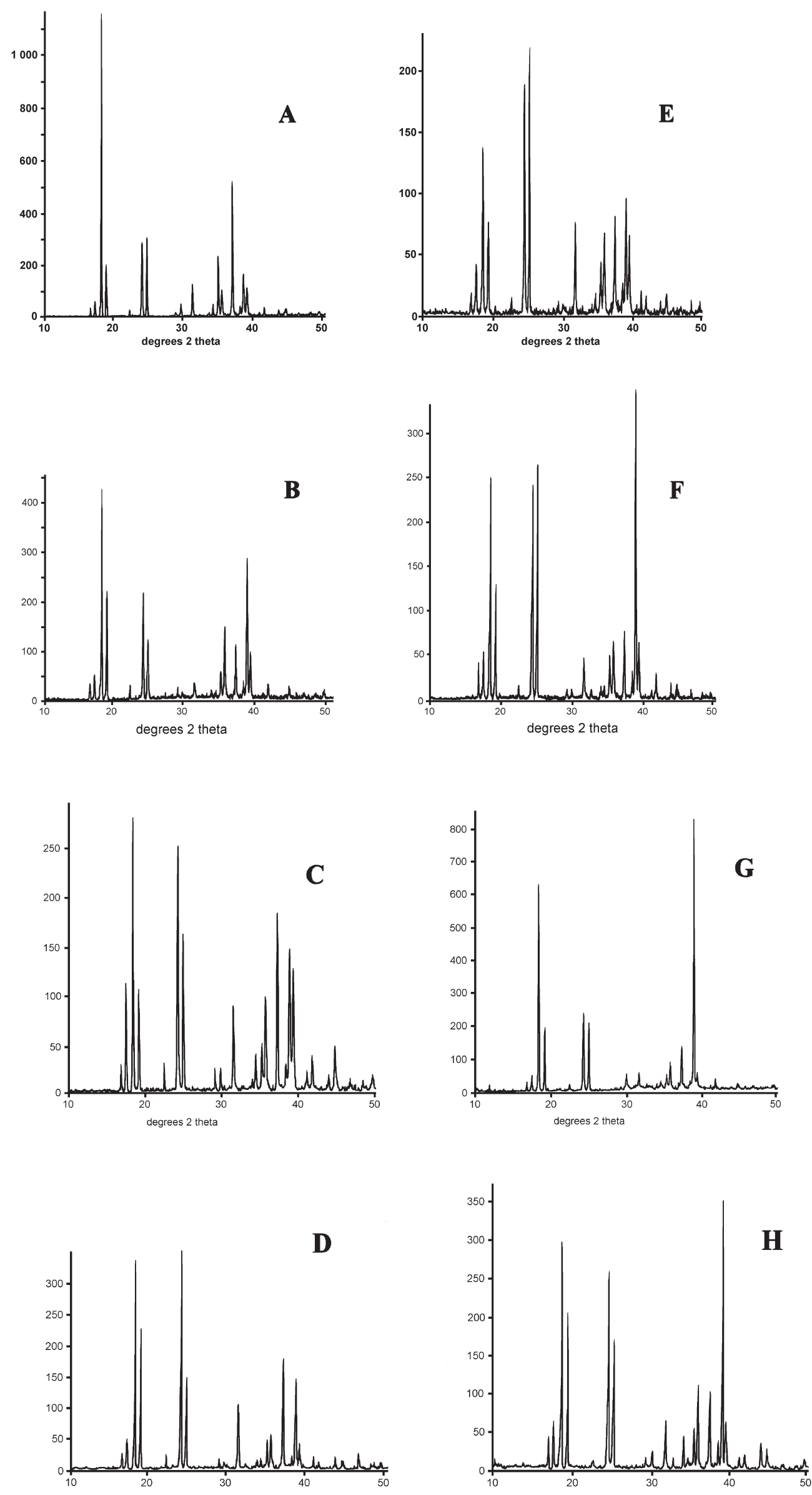

degrees 2 theta

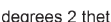

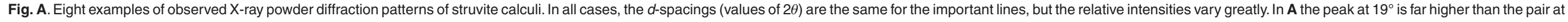

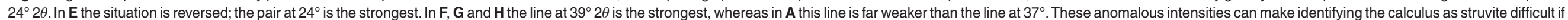
( high backgrounds, nor are there the broad peaks due to poorly crystalline hydroxyl apatite $\left(2.81-2.72 \AA \cdot 37-38^{\circ} 2 \theta\right)$. 


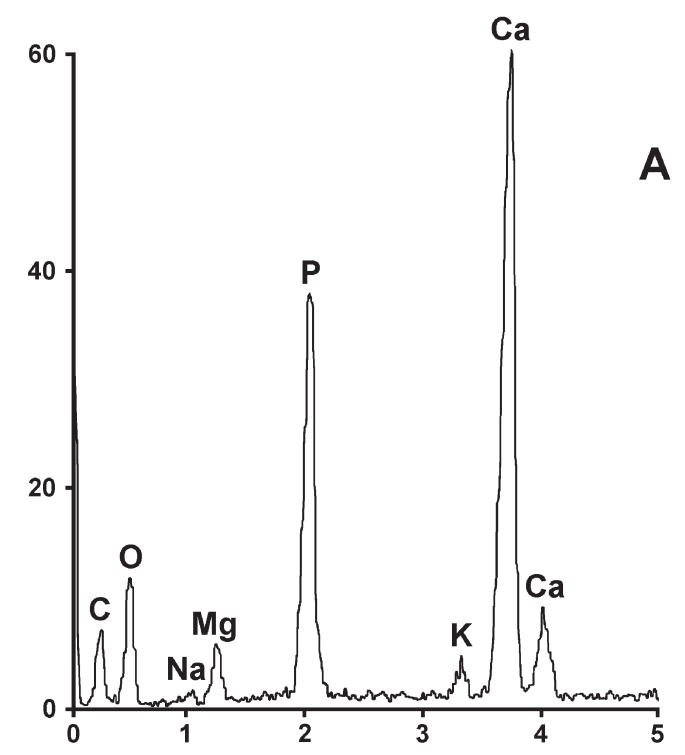

$\mathrm{keV}$
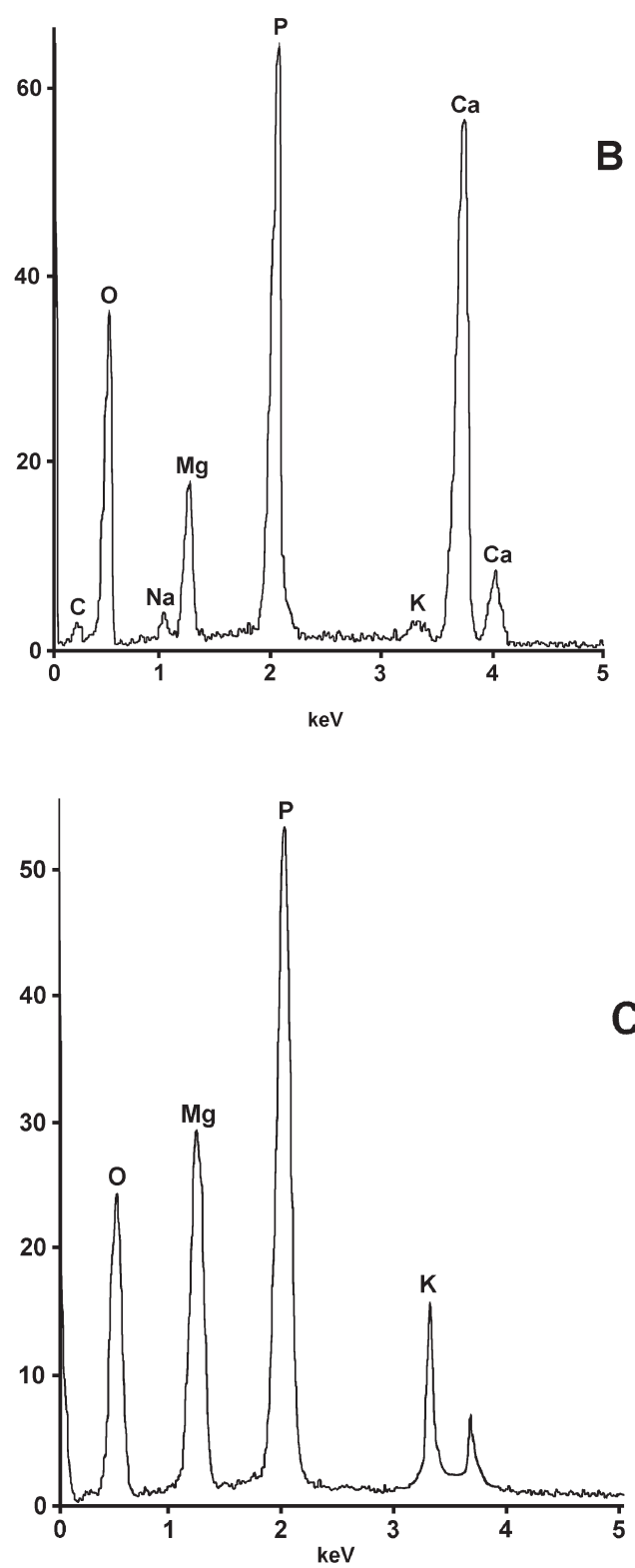

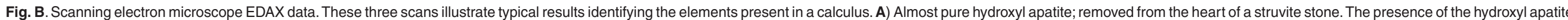

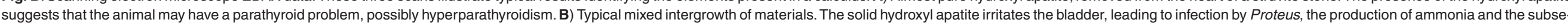

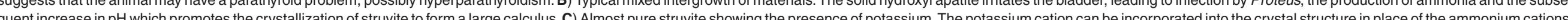
which have the same radius (i.e. isomorphous replacement). 


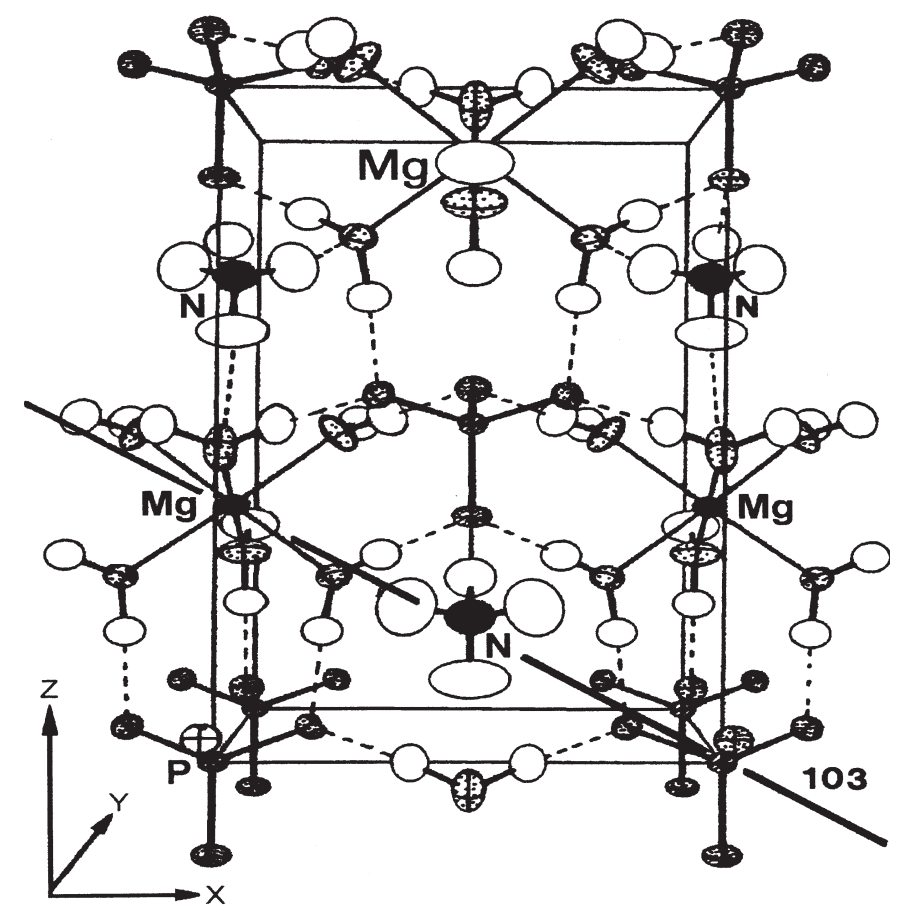

Fig. C. Projection of the struvite crystal structure along the $b$-axis (taken from ref. 7, Fig. 1), showing that the site occupied by the $\mathrm{NH}_{4}{ }^{+}$ions lies on the $101,103,200$ and 002 planes. The trace of the 103 plane is marked; note how it includes the $\mathrm{Mg}, \mathrm{N}$ and $\mathrm{P}$ atoms.

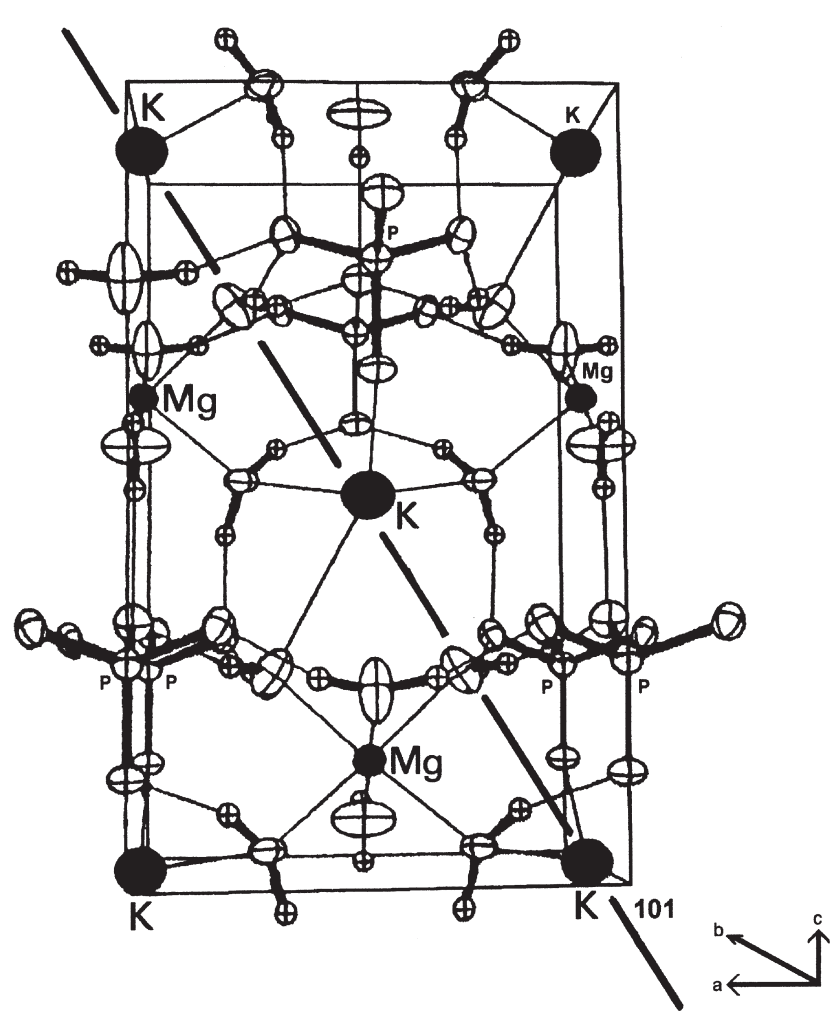

Fig. D. Projection of the crystal structure of the potassium analogue of struvite along the $b$-axis (taken from ref. 6, Fig 1) rotated $180^{\circ}$ in the plane of the paper. It shows that the sites occupied by the $\mathrm{K}^{+}$ion which, like the $\mathrm{NH}_{4}{ }^{+}$ion, lie on the 101 , 103,200 , and 002 planes, and diffraction from these planes should be most affected by the replacement of $\mathrm{NH}_{4}^{+}$by $\mathrm{K}^{+}$. The trace of the 101 plane through the $\mathrm{K}^{+}$ions is marked. The potassium ion $\left(\mathrm{K}^{+}\right)$corresponds in space with the ammonium ion $\left(\mathrm{NH}_{4}^{+}\right)$in Fig. 2 . 